\title{
Water Poverty Assessment in Olorunsogo Local Government Area of Oyo State, Nigeria
}

\author{
P.I. Ifabiyi ${ }^{1}$, B. Oladele ${ }^{1}$, and Salau Wahab ${ }^{2 *}$ \\ ${ }^{1}$ Department of Geography and Environmental Management, Faculty of Social Sciences, \\ University of Ilorin, PMB 1515, Ilorin, Nigeria \\ ${ }^{2}$ Department of Geography, Faculty of Humanities, Management and Social Sciences, Federal \\ University of Kashere, PMB 0182, Gombe State, Nigeria \\ *Corresponding Author: salawiy@ fukashere.edu.ng
}

Received 12 August 2019/ Revised 21 December 2019/ Accepted 5 January 2020/ Published 10 April 2020

\begin{abstract}
Poor access to water is often linked to poverty, human welfare, health, nutritional status, and household labour. This paper is aimed at contributing to the debate surrounding water poverty in the rural areas. Primary data obtained covering water resources, access, capacity, uses, and environment were collected using closed-ended questionnaires. Altogether, 370 household heads were sampled and were selected by systematic random sampling technique. Multiple correlations, factor analysis and multiple regression methods were used to determine the level of relationship between the Water Poverty Index (WPI) components. The results revealed that: WPI is the highest in Elenke/Sagbo (72.3\%) and the lowest in Onigbeti II/Sagbon (55.5\%). Also, WPI has a strong positive relationship with resources $(r=.656)$, capacity $(r=.705)$ and environment at $95 \%$. Percentages of explanations of WPI ranges from $86.45 \%$ in Onigbeti I to $50.99 \%$ in Aboke.The results of multiple regression between WPI and components showed that components were weak predictors in 5 wards (Onigbeti III \&IV, Onigbeti II , Onigbeti I, Seriki Agbele Aboke and Abogun wards). The paper posits that access to water in Olorunsogo Local Government Area (LGA) is generally reasonable. The paper suggests stronger government presence to improve and sustain the level of access.
\end{abstract}

Keywords : Water Poverty; Access; Capacity; Uses; Environment; Resources; Factor Analysis

\section{Introduction}

In 2002, the United Nations Development Programme (UNDP) ranked Nigeria as the $26^{\text {th }}$ poorest nation in the world. A relevant poverty type in Nigeria is that of water. Waterrelated poverty emerges when water resources constrain or impact upon people's livelihood options and assets. Water poverty arises as a result of inadequate availability of water or lack of proper accessibility to potable water for man's use and consumption. Water itself is an essential 
resource to man and it takes up a vital role in everyday activities of man. It is of great importance for domestic, cultural and various industrial uses. It harbors various life forms which are generally classified as hydrophytes and aquatic animals. According to the World Health Organization (WHO), a person requires roughly 25 liters of water per day to promote healthy living.

With man's ever demanding attitude for water and other climatological factors, the supply of water has drastically reduced over the years. This tends to exert stress on the available water resources. In other words the available water may become insufficient for the demanding population. This could be a result of the increase in human population. Water poverty is measured by the water poverty index (WPI) (Falkenmark et al., 1989; Sullivan, 2002; Ifabiyi \& Ogunbode, 2004; Falkenmark \& Rockstron, 2004; Heideck, 2006; Fenwick, 2019). Water Poverty tends to prevail in developing and less developed nations of the world where there are improper management of water in supply, usage and recycling. Water scarcity; may results in environmental, agricultural, and various economical and health issues. The finite nature of renewable fresh water makes it critical to examinenatural resources in the context of population growth. As population grow, the average amount of renewable fresh water available to each person declines.

Hence, hydrologists and other water experts agree that when certain ratios of water stress and outright scarcity are all but inevitable, then the population is heading towards water poverty. Water poverty has various implications on national development. In Nigeria, studies of water supply are mainly focused on water supply and demand with little emphasis on water scarcity and water poverty (Ifabiyi \& Ogunbode, 2014) despite the fact that water scarcity has already been widely experienced. Spatial and temporal analysis can reduce the potential for water poverty in certain areas (Kallio et al., 2018). Precipitation Index, Vegetation Condition Index, and Soil Moisture Content Index affect the potential for drought in an area (Mohmmed et al., 2018). Water quality can affect the health and welfare of the community in the long term (Borgomeo et al., 2018). One of the government policies that greatly influences the development of settlements in cities is by displacing settlements that are unable to provide access to quality water (Davis \& Ryan, 2017). Developing countries need to pay attention to the distribution of clean water in each region due to its vulnerability to poverty aspects. The above studies do not discuss the relationship between the Water Poverty Index, Resources, Access, 
Capacity, Uses and Environment in a comprehensive manner. It is crucial to conduct this study due to the fact that community needs related to clean water are not only related to physical aspects, but also often related to social problems. Access and capacity are novel aspects to study and relate to aspects of nature and the environment. This study is aimed at contributing to the debate surrounding water poverty in rural areas.

\section{Area of Study}

Olorunsogo Local Government is located in the Northern part of Oyo State, Nigeria. Its coordinates are lat $8^{\circ} 45^{\prime} 0$ ' $\mathrm{N}$ and long $4^{\circ} 7^{\prime} 0$ ' 'E. It is one of the 33 Local Governments in Oyo State Nigeria. Its headquarters is in the town of Igbeti. It has an area of $1,069 \mathrm{~m}^{2}$ and a population of 81,759 at the 2006 census. It has 10 wards as shown in the Table 1.

\begin{tabular}{cc} 
Table & \multicolumn{2}{c}{ List of Wards in Olorunsogo Local Government Area } \\
\cline { 2 - 3 } S/N & Name \\
\cline { 1 - 2 } i. & Aboke ( AboyunOgun) \\
ii.. & ApataAlaje \\
iii. & Elenke/ sagbo \\
iv. & Ikolaba/ Obadimo \\
v. & Onigbeti I \\
vi. & Onigbeti II/ Sagbon \\
vii. & Onigbeti III \& IV \\
viii. & Opa/ Ogundiran \\
ix. & Seriki I \& (Abosino) \\
x. & Seriki II \& (Agbele) \\
\hline
\end{tabular}

The climate of the area is characterized by dry and wet seasons with high relative humidity. Dry season is between November- March while the wet season starts from April and ends in October. Average daily temperature ranges between $25^{\circ} \mathrm{C}\left(77.0^{\circ} \mathrm{F}\right)$ and $35^{\circ} \mathrm{C}\left(95.0^{\circ} \mathrm{F}\right)$ almost throughout the year. Precipitation varies from an average of $1200 \mathrm{~mm}$. However, during the wet season,high surface runoff with high humidity usually occurs. This study area has the guinea savannah vegetation type. Aquifers are of restricted vertical and lateral extent, but since the tropical climate affords the necessary conditions for deep and rapid chemical decay, thick, sandy clayey, lateritic overburdens serve as potential aquifers. This area is underlain by metamorphic rocks of the basement complex, which outcrop over many parts. Geographical features such as the Iyamopo and the Agbele hill are the dominant relief systems. Rocks consist 
of old hard rocks and dome shaped inselberg hills, which gently rise from about 500metres in the southern part and reaching a height of about 1,219metres above sea level in the northern part around Igbeti town. The Local Government Area has been regarded as suitable for agricultural purposes. Igbeti has a large food market with marketers from every part of Nigeria. Market products include: yam, yam flour and cassava flour. A large proportion of the residents engage in agriculture either in small or in large scale. The extensive marble deposit in Igbeti led to the presence of the Nigerian Mining Company Limited in1984. Quarrying is also a prominent activity in the LGA. Tourism is also an important activity due to the prominent hills and the Old Oyo National Park which extend to Ogundiran area of Olorunsogo Local Government Area.

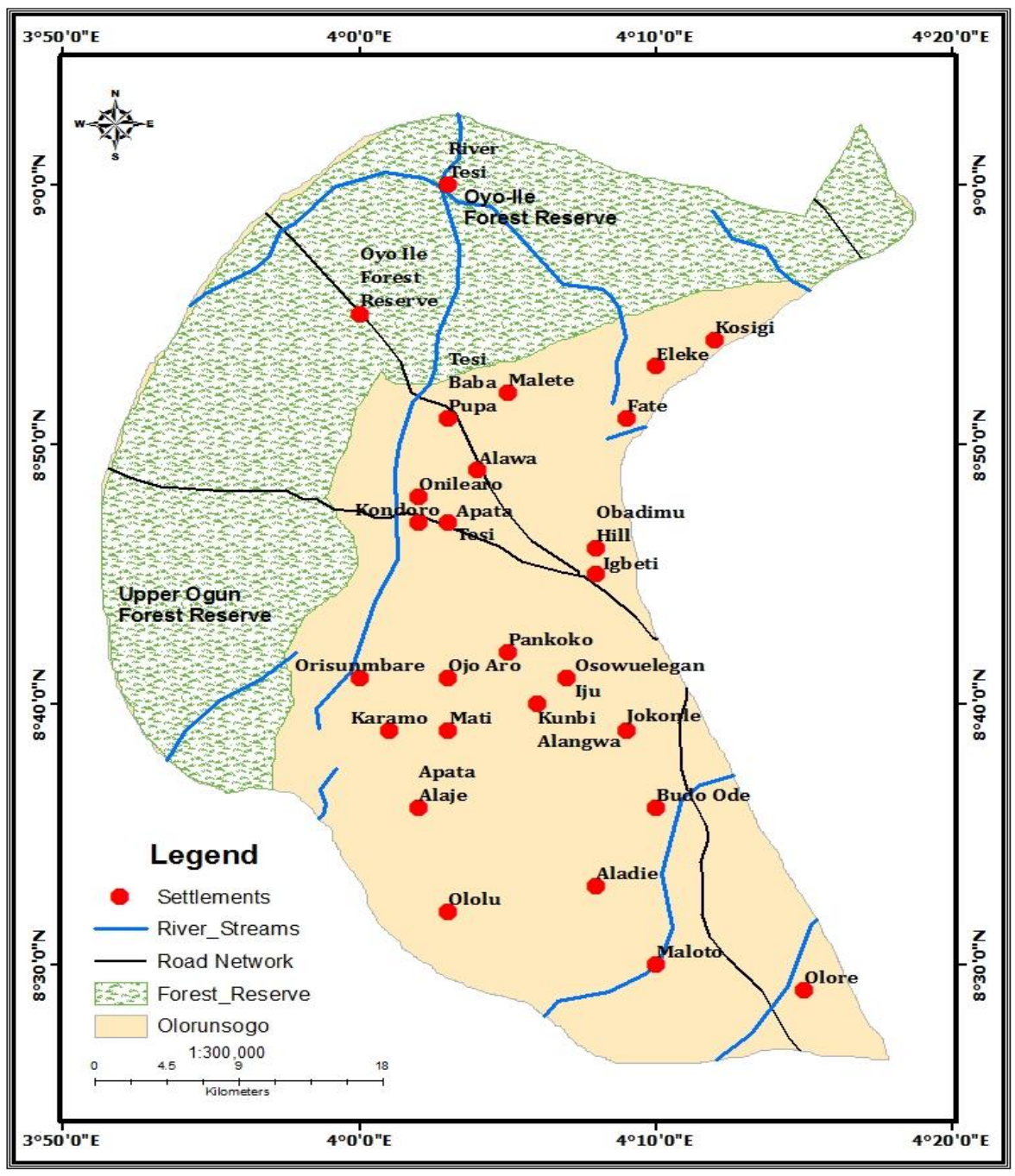

Figure 1. Igbeti and Environs 


\section{Methods}

Data used in this study were collected by structured questionnaires. Data were sourced from the 10 political wards in Olorunsogo Local Government area of Oyo state. These include: information on water availability, accessibility to water supply, capacity of water resources, water use and environment. Online sample size calculator was used to determine the total number of questionnaires to be administered after estimating the population size using equation 1 .

$\operatorname{Pn}=\operatorname{Po}(1+r / 100)^{x}$

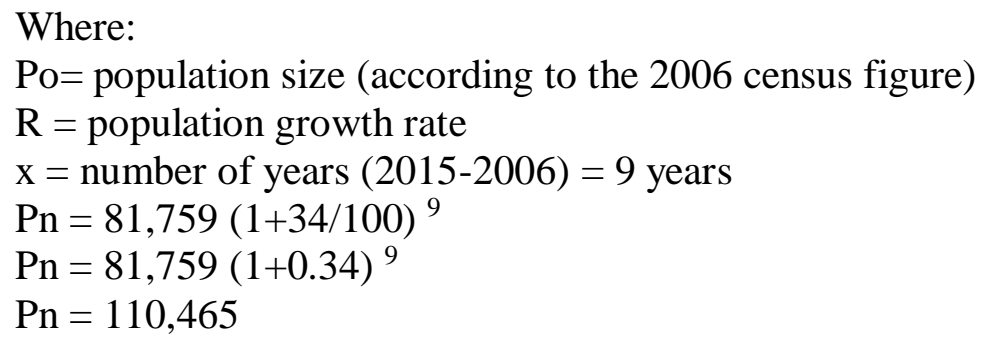

With the population figure of 110,465 and a household size of 8 , the Krejice and Morgan sample size calculator arrived at the use of 370 questionnaires with 37 copies of questionnaires for each of the 10 wards in the LGA. A closed ended questionnaire was used in which the respondents were allowed to choose from the available options only. Systematic random sampling technique was adopted to select respondents in the 10 wards.

Accessibility to water can be quantified by using several indicators such as: human development index, water supply stress index, population growth impacts of water resource availability, e.t.c. out of the above indices, the water poverty index (WPI) was used because it is found to be the most effective tool to access water availability of the regions. WPI is easy to calculate, easy to implement and is mainly based on the existing data. Water Poverty Index (WPI) as defined by Sullivan et al. (2002) is mathematically defined as: 


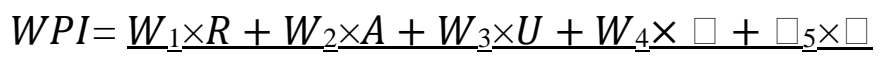

$$
\square_{1}+\square_{2}+\square_{3}+\square_{4}+\square 5
$$

The weights $\left(W_{\mathrm{i}}\right)$ applied to each of the five components $(R, A, C, U \& E)$ are constrained to be non-negative and sum to unity. All parameters are standardized to fall in the range of 0-1, where value 0 is assigned to the poorest level (i.e highest degree of water poverty), and 1 to optimum conditions. The WPI defines water poverty according to the five components, i.e.: resources, access, capacity, use and environment.

\section{Results and Discussion}

\subsection{Components of Water Poverty}

The score of resources in this study is $87.6 \%$ in Elenke /Sagbo ward, suggesting that the ward had more than one sources of water. The lowest availability was in Apata /Alaja ward with limited sources of water. Generally, the LGA had reasonable score on resources with all the wards scoring above $50 \%$. Rain fell for a minimum of 7 months. Access to water was the highest in Apata/Alaje with a score of $89.3 \%$ and the lowest in Seriki II with 50\%. All wards scored above 50\%. There were many hand dug wells in this ward. Capacity was at its highest score in Elenke/ Sagbo ward (67.6\%). This was an expected result due to the significant number of employed people in this ward. Capacity scored above $50 \%$ in all the political wards. Uses of water had the highest score in Ikolaba/Obadimo ward. This was expected in view of the fact that water was used in this ward for block making and other cottage industrial uses. The lowest value of $40 \%$ was recorded in Onigbeti/Sagbon ward. Uses of water were largely domestic in the LGA. Aboke/Aboyun-Ogun had a score of $87.1 \%$, which was the highest value; the lowest value was in Onigbeti II/ Sagbon ward. Environment plays a dominant role in water supply as it is responsible for sustaining river flow and groundwater level. 

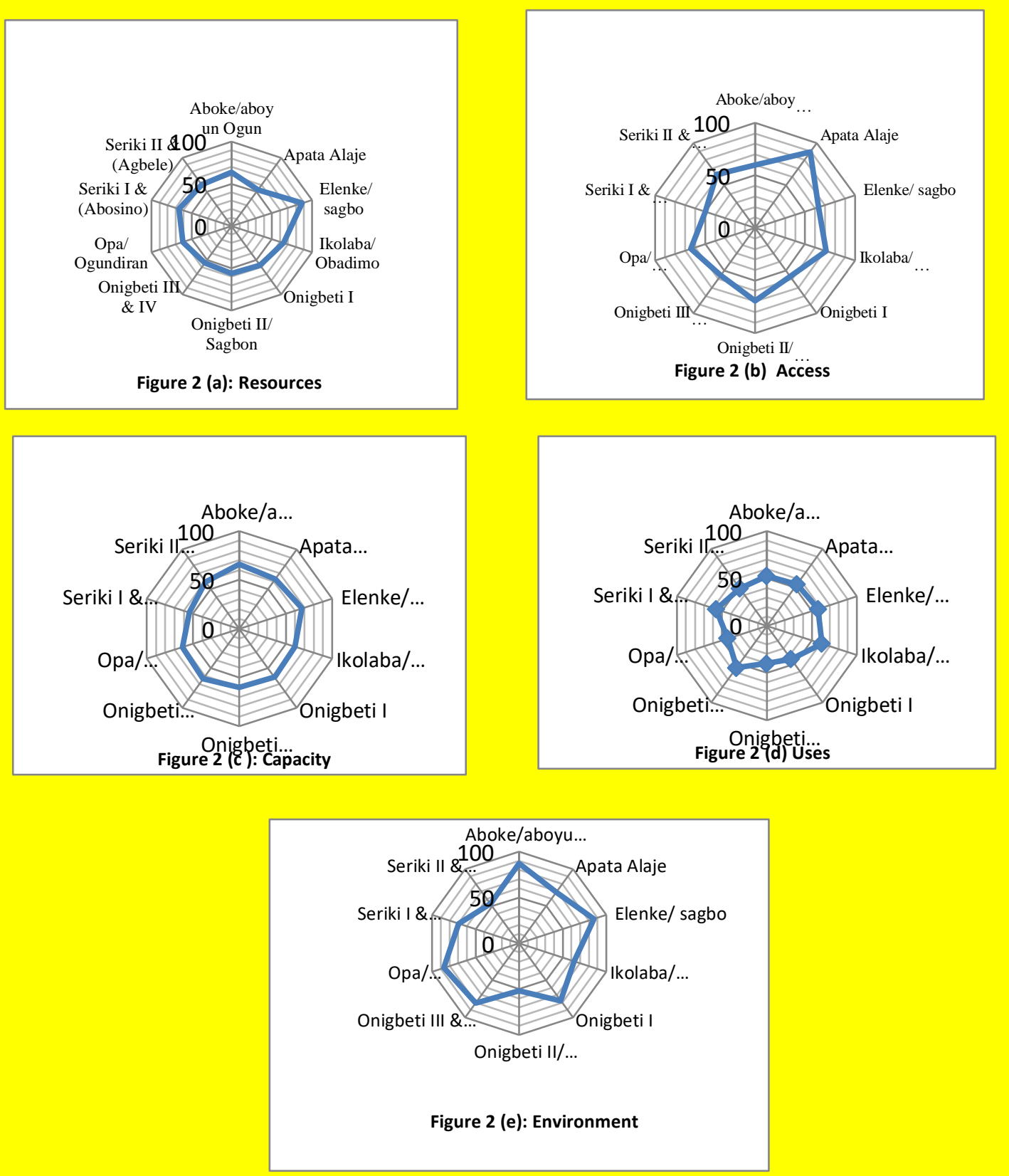

Figure 2. Pattern of distribution of water poverty components in the political wards: Water Poverty Pattern 
Figure 2 depicts the patterns of WPI from Aboke/ AboyunOgun ward to Seriki II \& Agbele ward of the Local Government Area. Water resources were the highest in Elenke/ Sagbo with $87.6 \%$ and lowest in ApataAlaje (53.1\%). Water was most accessible in Apata Alaje $(89.3 \%)$ and least accessible in Seriki (Abosino). Capacity was the highest in Elenke/ Sagbo and lowest (53.8\%)in SerikiAbosino. Water use was the highest in Ikolaba/Obadimo ward with (61.2\%) and lowest in Onigbeti II/ Sagbon with 40\%. The environment was clean and free from most environmental challenges with the highest value in Aboke/Aboyun Ogun (87.1\%) and lowest in Onigbeti II/ Sagbon with 51.9\%. On the values of WPI, Elenke/ Sagbo was the highest (72.3\%), while Onigbeti II/Sagbon ward was the lowest with 55.5\%. The value recorded in this study was relatively higher than the value of $44 \%$ obtained as the national value for Nigeria and was higher than that of many African nations (Egypt=28.71\%, Niger $=44 \%$, Ghana $=47.50 \%$, South Africa $=41.51 \%$ ) but lower than that of some other countries (Equatorial Guinea $=87.99 \%$, Gabon $78.15 \%$, Angola $=65.86 \%$, etc). The value range was medium to low, indeed none of the communities had severe water poverty situation (Table 3). This suggests that the level of scarcity is not severe. Water resources is generally relatively available.

The values recorded in Table 3 showed that there was reasonable access to water in the LGA as no ward had less than $55 \%$ access. This feat was made possible as a result of government intervention in water provision and due to the numerous hand-dug wells which was common to almost every household. Igbeti LGA is situated within interfluves with relatively rich, shallow regolith aquifer, which supply water reasonably to shallow wells. In addition to this, government also provided a number of hand pumps and motorized boreholes within the various communities in the study area. Hence, this had alleviated the burden of water scarcity. 

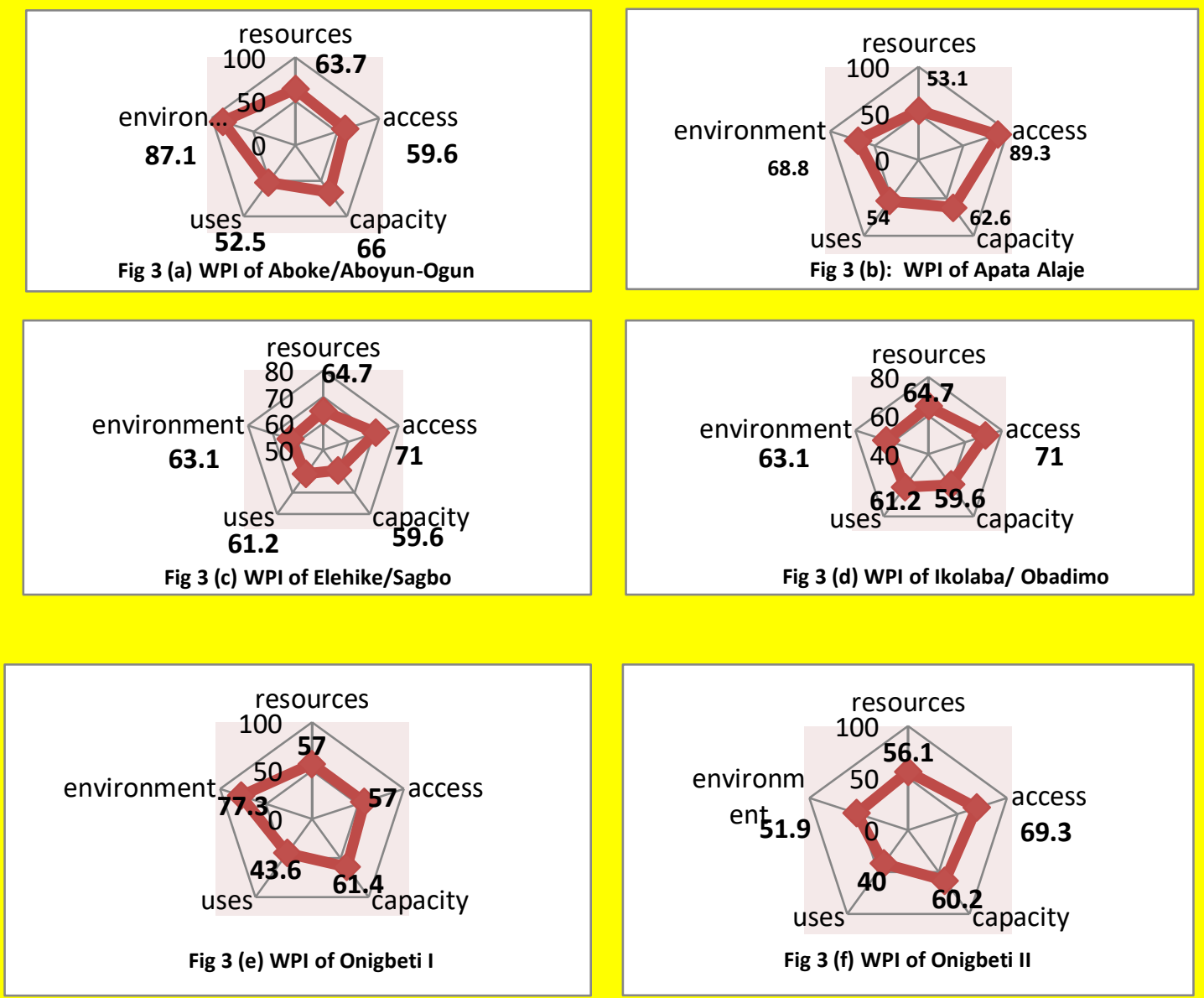

Fig 3 (e) WPI of Onigbeti I
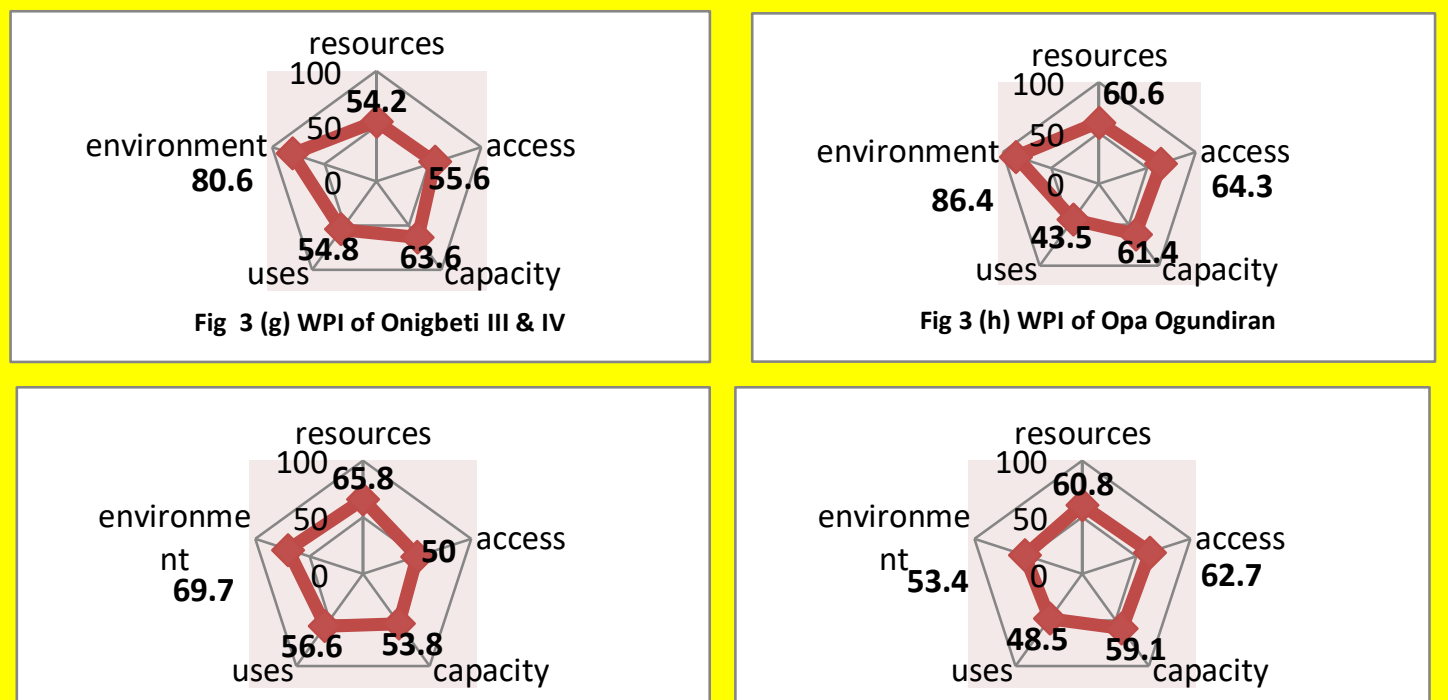

Fig 3 Fig 2 (i) WPI of Seriki Abosino

Fig 3 (j) WPI of Seriki II \&Agbele

Figure 3. Pentagrams representation of the WPI in Olorunsogo Local Government Area 
4.2 The Relationships between WPI, Resources, Access, Capacity, Uses and Environment

As indicated in Table 2, the relationship between WPI and its five components (resources, access, capacity, uses and environment) were used to calculate water poverty. WPI has a strong positive relationship with resources $(\mathrm{r}=.656)$, capacity $(\mathrm{r}=.705)$ and environment $(\mathrm{r}=0.683)$ which are statistically significant at $95 \%$ confidence level, this suggest that as resources, capacity and environmental factor increases in the study, WPI also increases. On the other hand, WPI has a weak and mild positive relationship with access $(r=.240)$ and uses $(r=$ .566) respectively which were not statistically significant at $95 \%$ confidence level. However, access has a weak negative relationship with resources $(r=-.215)$ and environment $(r=-.289)$ but the relationships are not statistically significant at $95 \%$ confidence level. Every component exhibits weak positive relationship with each other. The weak relationship between the WPI and water accessibility can be explained by the distance to the source of water and the household size. These two factors have a high magnitude of association with access $(r=.240)$ in the study area. Resource availability in the study area is also high as farming activities take place within the Local Government and this enhances the trading activities which includes foreigners from several parts of the country. Trade itself is a catalyst to economic growth and this has led to the provision of infrastructural facilities which include water supply in the study area.

Water usage or water demand in the study area is about $70 \%$ of the availability. About $74 \%$ of this is diverted for agricultural use while the remaining $26 \%$ is accountable for domestic, industrial recreational, commercial, and other uses.

Table 2. Relationship between WPI, Resources, Access, Capacity, Uses and Environment

\begin{tabular}{lccccc}
\hline Components & Resources & Access & Capacity & Uses & Environment \\
\hline WPI & $.656^{*}$ & .240 & $.705^{*}$ & .566 & $.683^{*}$ \\
Resources & & -.215 & .321 & .422 & .340 \\
Access & & & .214 & .033 & -.289 \\
Capacity & & & & .051 & .589 \\
Uses & & & & & .173 \\
\hline
\end{tabular}


P.I. Ifabiyi et al / GEOSI Vol 5 No 1 (2020) 92-105

Table 3. Water Poverty Index (WPI) of Olorunsogo Local Government Area

\begin{tabular}{lcccccc}
\hline \multicolumn{1}{c}{ Ward } & Resources & Access & Capacity & Uses & Environment & WPI \\
\hline Aboke/aboyun Ogun & 63.7 & 59.6 & 66 & 52.5 & 87.1 & 65.7 Medium Low \\
Apata Alaje & 53.1 & 89.3 & 62.6 & 54 & 68.8 & 65.6 Medium Low \\
Elenke/ sagbo & 87.6 & 63.6 & 67.4 & 56.9 & 85.8 & 72.3 Low \\
Ikolaba/ Obadimo & 64.7 & 71 & 59.6 & 61.2 & 63.1 & 63.9 Medium Low \\
Onigbeti I & 57 & 57 & 61.4 & 43.6 & 77.3 & 59.3 Medium \\
Onigbeti II/ Sagbon & 56.1 & 69.3 & 60.2 & 40 & 51.9 & 55.5 High \\
Onigbeti III \& IV & 54.2 & 55.6 & 63.6 & 54.8 & 80.6 & 61.8 Medium Low \\
Opa/ Ogundiran & 60.6 & 64.3 & 61.4 & 43.5 & 86.4 & 63.2 Medium Low \\
SerikiI \& (Abosino) & 65.8 & 50 & 53.8 & 56.6 & 69.7 & 59.2 Medium \\
Seriki II \& (Agbele) & 60.8 & 62.7 & 59.1 & 48.5 & 53.4 & 56.9 Medium \\
\hline
\end{tabular}

Table 4. Determinants of water poverty in Olorunsogo LGA

\begin{tabular}{|c|c|c|c|c|}
\hline \multirow[b]{2}{*}{ Political Wards } & \multicolumn{4}{|c|}{ Multiple Regression Properties } \\
\hline & $\begin{array}{c}\text { Factor } \\
\%\end{array}$ & Regression & $\begin{array}{c}\text { Factor } \\
\text { Analysis } \\
\%\end{array}$ & $\begin{array}{c}\text { Regression } \\
\%\end{array}$ \\
\hline Aboke/ Aboye & Access & Nil & 54.99 & 31.71 \\
\hline Apata Alaje & $\begin{array}{c}\text { Capacity (31.71) } \\
\text { Resources (29.81) }\end{array}$ & $\begin{array}{l}\text { Resources (76.4) } \\
\text { Capacity(5) }\end{array}$ & 61.53 & 82.0 \\
\hline Ikolaba/Obadimo & $\begin{array}{c}\text { Usage (34.88) } \\
\text { Environment (23.70) }\end{array}$ & Environment (50) & 58.58 & 50.0 \\
\hline Onigbeti I & $\begin{array}{c}\text { Resources (35.24) } \\
\text { Access (29.1) } \\
\text { Capacity (22) }\end{array}$ & Resources (41.0) & 86.45 & 41.0 \\
\hline Onigbeti II & $\begin{array}{l}\text { Environment } \\
\text { Capacity }\end{array}$ & $\begin{array}{l}\text { Environment } \\
\text { Capacity }\end{array}$ & 65.28 & 2.90 \\
\hline Onigbeti III \& IV & $\begin{array}{l}\text { Resources } \\
\text { Usage }\end{array}$ & $\begin{array}{c}\text { Usage } \\
\text { Resources }\end{array}$ & 65.28 & 2.90 \\
\hline Ogunderin/Opa & $\begin{array}{l}\text { Resources } \\
\text { Access } \\
\text { Usage }\end{array}$ & $\begin{array}{l}\text { Resources } \\
\text { Usage }\end{array}$ & 77.70 & 96.5 \\
\hline Seriki/Abiso & $\begin{array}{l}\text { Usage } \\
\text { Access }\end{array}$ & Usage & 56.80 & 56.4 \\
\hline Seriki/ Agbele & $\begin{array}{l}\text { Environment } \\
\text { Resources } \\
\text { Capacity }\end{array}$ & - & 79.88 & 17.2 \\
\hline Elenko/Sagbo & $\begin{array}{l}\text { Resources } \\
\text { Access }\end{array}$ & $\begin{array}{l}\text { Resource } \\
\text { Access }\end{array}$ & 68.82 & 99.2 \\
\hline
\end{tabular}


The indices of water poverty differ in their dominance from ward to ward. As shown in Table 4. The resources had the highest rate of reoccurrence (6 times), access appeared 5 times, capacity and water uses featured 4 times, while environment featured only 3 times.This distributionsupportsthe relatively fair pattern of water access whereby at least all LGAs had WPI of greater than $50 \%$. Meanwhile, the percentages of explanation were generally strong, ranging from $86.45 \%$ in Onigbeti I to $50.99 \%$ in Aboke.

Previous studies discovered that, among others, community social status influences access and management to clean water (Ngarava et al., 2019), investment growth can affect the expansion of settlements in coastal areas and have an impact on water quality degradation (Hoque et al., 2019), land use for agriculture is more optimal when carried out in rural areas with consideration of market access and better water availability (Harmanny \& Malek, 2019), the majority of the poor finds it difficult to access clean water pipes due to cost issues (Carrard et al., 2019), increasing the ability of the community to manage water resources is needed to reduce social barriers in the use of clean water (Panthi et al., 2019). Meanwhile, this study found the role of access and capacity of the community in reducing the potential for lack of clean water. The results of this study shows that access to clean water is not only related to natural conditions such as aquifers, but also related to the ability of governments and communities to manage clean water. Providing access to the community does not only take the form of water infrastructure development, but also reduces prices to access the water infrastructure.

The relationship between WPI and component was slightly different in many wards, such as Onigbeti III \&IV, Onigbeti II , Onigbeti I, Seriki Agbele Aboke and Abogun. The components of WPI, provided weak explanations, suggesting that in these wards, access to water may be due to other reasons such as politics, culture, technology, and other variants which are beyond the scope of this papers. However, in the other 5 LGAs, WPI were better predictors of water access.

\section{Conclusion}

Water supply in the study area was adequate; therefore, there was low level of water scarcity in the study area. The results revealed that: WPI was the highest in Elenke/Sagbo (72.3\%), wasthe lowest in Onigbeti II/Sagbon (55.5\%).This supportedthe relatively high pattern 
of water access, whereby at least all LGA had WPI of greater than 50\%. The paper posits that access to water in Olorunsogo LGA was generally reasonable and that the impacts of WPI differed from ward to ward as certain variables were dominant in certain ward compared to the others. The paper suggests stronger government presence to improve and sustain the level of access and poverty margin.

\section{Conflict of Interest}

The authors declare that there is no conflict of interest with any financial, personal, or other relationships with other people or organizations related to the material discussed in the article.

\section{References}

Borgomeo, E., Hall, J. W., \& Salehin, M. (2018). Avoiding the water-poverty trap: Insights from a conceptual human-water dynamical model for coastal bangladesh. International Journal of Water Resources Development, 34(6), 900-922. doi:10.1080/07900627.2017.1331842

Carrard, N., Madden, B., Chong, J., Grant, M., Nghiêm, T. P., Bùi, L. H., . . Willetts, J. (2019). Are piped water services reaching poor households? empirical evidence from rural viet nam. Water Research, 153, 239-250. doi:10.1016/j.watres.2019.01.026

Davis, M. F., \& Ryan, N. (2017). Inconvenient human rights: Water and sanitation in Sweden's informal roma settlements. Health and Human Rights, 19(2), 61-72.

Falkenmark, M. and Rockström, J. (2004).Balancing Water for Humans and Nature- the new Approach in Ecohydrology.London: Earth scan.

Falkenmark, M., Lundqvist, J., \&Widstrand, C. (1989).Macro-scale water scarcity Federal Republic of Nigeria (2000), Water Supply and Sanitation Interim Strategies Note

Fenwick, C. (2019). Identifying the Water Poor: An Indicator Approach to Assessing Poverty in Rural Mexico. A PhD Thesis submitted to Department of Civil, Environmental and Geomatic Engineering, University College, London. Pg. 270.

Guppy, L. (2014) the water poverty index in rural Cambodia and Vietnam: a holistic snapshot to improve water management planning. Natural Resources Forum. 38: 203-219

Harmanny, K. S., \& Malek, Ž. (2019). Adaptations in irrigated agriculture in the mediterranean region: An overview and spatial analysis of implemented strategies. Regional Environmental Change, 19(5), 1401-1416. doi:10.1007/s10113-019-01494-8 
Hoque, S. F., Hope, R., Arif, S. T., Akhter, T., Naz, M., \& Salehin, M. (2019). A socialecological analysis of drinking water risks in coastal bangladesh. Science of the Total Environment, 679, 23-34. doi:10.1016/j.scitotenv.2019.04.359

Ifabiyi I.P. \& Ogunbode T. O. (2014): The Use of Composite Water Poverty Index in Assessing Water Scarcity in the Rural Areas of Oyo State Nigeria. An International Journal of Science and Technology, 3 (2):51-65.

Kallio, M., Guillaume, J. H. A., Kummu, M., \& Virrantaus, K. (2018). Spatial variation in seasonal water poverty index for laos: An application of geographically weighted principal component analysis. Social Indicators Research, 140(3), 1131-1157. doi:10.1007/s11205017-1819-6

Kini, J. (2017). Inclusive water poverty index: A holistic approach for helping local water and sanitation services planning. Water Policy, 19(4), 758-772. doi:10.2166/wp.2017.075

Maheswari, J.U. \& Chaithanya, S.M. (2015) water poverty index facts and figures- A review. International Civil Engineering Symposium. DOI: 10.13140/RG.2.13681.1369.

Mohmmed, A., Zhang, K., Kabenge, M., Keesstra, S., Cerdà, A., Reuben, M., . . Ali, A. A. S. (2018). Analysis of drought and vulnerability in the north darfur region of sudan. Land Degradation and Development, 29(12), 4424-4438. doi:10.1002/ldr.3180

Ngarava, S., Zhou, L., \& Monde, N. (2019). Gendered water insecurity: A structural equation approach for female headed households in south africa. Water (Switzerland), 11(12) doi:10.3390/w11122491

Panthi, J., Khatiwada, K. R., Shrestha, M. L., \& Dahal, P. (2019). Water poverty in the context of climate change: A case study from karnali river basin in nepal himalaya. International Journal of River Basin Management, 17(2), 243-250. doi:10.1080/15715124.2018.1531421

Sullivan, C. (2002), Calculating a water poverty index. World Development Journal, 30 (7): 1195-1210.

Umamahheswari, J., Bukke, S. \& Chaithanya, S.M. (2017) Water poverty index as a water management :A micro level study in Tamil Nadu, India. A Paper Presented $6^{\text {th }}$ Conference on Water and Food Management (ICWFM, 2017) 